\title{
Conventional versus minimally-invasive cervical discectomy for treatment of severe degenerative disease at C5-C6: a biomechanical comparison using a model of the full cervical spine and finite element analysis
}

\author{
Yuan Li, Gladius Lewis \\ Department of Mechanical Engineering, The University of Memphis, Memphis, USA. \\ Email: glewis@memphis.edu
}

Received 19 February 2011; revised 7 April 2011; accepted 5 June 2011.

\section{ABSTRACT}

The purpose of this study was to determine the differences in biomechanical responses of tissues in the cervical spine when pain and other problems secondary to severe disc degeneration disease are surgically treated by conventional discectomy (CONDIS) compared to minimally-invasive discectomy (MIVDIS). A validated three-dimensional model of an intact, healthy, adult full cervical spine (C1-C7) (INT) was constructed. This model was then modified to create two models, one simulating each of the above-mentioned two techniques for discectomy of the severely degenerated C5-C6 disc. For each of these three models, we used the finite element analysis method to obtain four biomechanical parameters at various tissues in the model, under seven different physiologically relevant loadings. For each of the biomechanical parameters, the results were expressed as relative change in its value when a specified combination of simulated discectomy model and applied loading was used, with respect to the corresponding value in the intact model. We then computed the value of a composite biomechanical performance index (CBPI) for CONDIS and MIVDIS models, with this value incorporating all of the aforementioned relative changes. We found that CBPI was marginally lower for MIVDIS model. This trend is the same as that reported for the relative complications rate and outcome measures following conventional and minimally-invasive discectomies in the lumbar spine. From a healthcare perspective, one implication of our finding is that minimally-invasive cervical discectomy should be considered an attractive option provided that detailed patient selection criteria are clearly defined and strictly followed.
Keywords: Finite Element Analysis (FEA); Cervical Spine; Disc Degeneration; Discectomy

\section{INTRODUCTION}

When conservative treatments, such as analgesics and braces, do not provide relief from the pain due to/associated with severe degenerative disc disease (DDD) in the cervical spine, there are a host of surgical methods that may be employed. These are anterior cervical discectomy followed by fusion (ACDF) (the most popular method) [1,2]; discectomy without fusion (DISWF) (used in a modest number of cases) [1,3-9]; percutaneous nucleotomy (used in a few cases) [10]; total disc replacement (recently approved by regulatory bodies, such as the US Food and Drug Administration) [11-13]; and nucleus pulposus (NP) replacement [14] and intervertebral disc transplant [15] (each being an emerging option).

There are two variants of DISWF. One is referred to as the conventional, standard, or open approach $[1,3,4]$ while the other is a family of minimally-invasive procedures, namely, percutaneous cervical discectomy, percutaneous endoscopic cervical discectomy, percutaneous cervical laser decompression, percutaneous microcompressive endoscopic cervical discectomy microdiscectomy [5-9]. Arguably, the two most important driving forces for the introduction and increasing popularity of the latter techniques are to utilize a narrower surgical entry window and to reduce the amount of soft tissue that is disrupted and/or excised - in addition to the affected parts of the disc - compared to the former procedure [16]. A biomechanical comparison of conventional and minimally-invasive techniques for discectomy in the cervical spine is lacking. The purpose of the present study was to perform such a comparison. To this end, 1) we used a validated three-dimensional solid model of the 
full cervical spine, in which severe degeneration of the C5-C6 disc was simulated, modifications of this model to simulate both conventional and minimally-invasive discectomy techniques, and the finite element analysis (FEA) method; and 2) we determinedan assortment of biomechanical parameters in a large number of hard and soft tissues in each of the models, when subjected to a number of different physiologically relevant loadings.

\section{FINITE ELEMENT ANALYSIS}

We constructed three three-dimensional (3D) solid C1-C7 models, one representing an intact, healthy, adult spine and the other twobeing modifications of this spineto simulate conventional and minimally-invasive techniques for discectomy of a severely degenerated C5-C6 disc.

\subsection{Model of Intact, Healthy, Adult Spine}

This model (hereafter, INT Model) comprised the vertebral bodies, the bony posterior elements (transverse processes, pedicles, laminae, spinous processes, and facet joints), the discs, the endplates, and the ligaments at each level (Figure 1). It was built from digitized quantitative axial computed tomography scans/images of an adult male cadaver that were imported from the Visible Human Project ${ }^{\circledR}$ dataset (National Library of Medicine, Bethesda, MD, USA). The values of the material properties of all the tissues in the model are given in Table 1. In our previous report [25], we gave details of the procedures used to construct this model; showed that the model had geometric fidelity vis a vis the cervical spine of healthy, male adults; highlighted the fact that the natural lordosis of all the functional spinal units

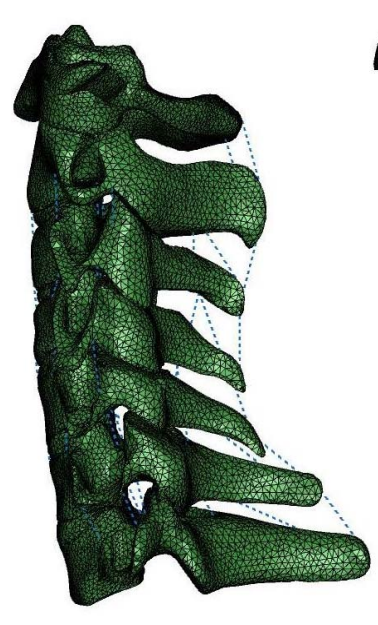

(a)

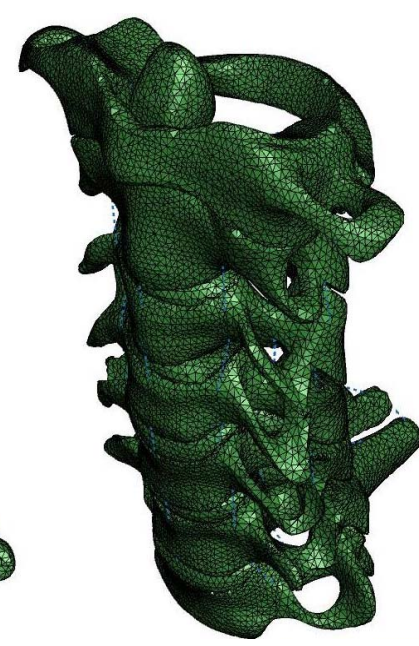

(b)
Figure 1. Two views of the converged finite element mesh of the INT model.
(FSUs) was preserved in the model; described all of the steps used to generate the finite element mesh from the model; provided details of the convergence test; and provided details of the validation exercise. In the validation work, we compared our FEA results obtained using INT model to those from two experimental studies, namely, those by Panjabi et al. [26] and by Wheeldon et al. [27].

\subsection{Models of Severely Degenerated Spine and Simulated Discectomies}

We created a model of a spine in which there was severe degeneration of the disc at C5-C6 (corresponding to grade4 in a classification system that is used in clinical assessment of cervical disc degeneration [28]). Specifically, to do this, we: 1) put the anterior and posterior heights of the disc $=3.5 \mathrm{~mm}$ and $2.0 \mathrm{~mm}$, respectively, each being $75 \%$ of the value in the healthy disc [29]; 2) assigned the modulus of elasticity (E) of the ground substance in the annulus fibrosus (AF) to be $8.4 \mathrm{MPa}$, this being two times that for the ground substance in the AF in the healthy disc [29]; 3) took the volume fraction of the elastic fibers in the ground substance in the $\mathrm{AF}=$ $15 \%$, this being $75 \%$ that for a healthy disc [30]; and 4 ) used $\mathrm{E}$ for the $\mathrm{NP}=8.4 \mathrm{MPa}$, this being two times that for the ground substance in the AF in the healthy disc [29].

Conventional discectomy was simulated using the method described by Nandoe-Tiwari et al. [3]. Thus, the inferior endplate on C5, the C5-C6 disc, the ALL at C5-C6, and the superior endplate on C6 were all deleted and then the inferior surface of the $\mathrm{C} 5$ vertebral body and the superior surface of the C6 vertebral body were contoured so as to form an exact bond; that is, they were fully bonded. The resulting model is herein designated CONDIS Model.

Minimally-invasive discectomy was simulated by using aspects of the technique described by Chiu et al. [5] and by Ahn et al. [6]. This meant shaving all around the periphery of the AF, such that the final volume of the AF was $85 \%$ of that in INT model, and reducing the volume of the NP to be $17 \%$ of that in INT model. The resulting model is herein designated MIVDIS Model.

For the simulated discectomy models, a validation exercise was not conducted because, to the best of our knowledge, there are no published appropriate experimentally-obtained results.

\subsection{Boundary Conditions and Loadings}

For each of the three models (INT, CONDIS, and MIVDIS Models), the loading was applied to the superior surface of $\mathrm{C} 1$ vertebral body while the inferior surface of C7 vertebral body was fully constrained in all 
Table 1. Element type and elastic properties of the tissues in the finite element model.

\begin{tabular}{|c|c|c|c|}
\hline Tissue & Element type & Elastic property & Reference(s) \\
\hline Cortical bone & $\begin{array}{l}\text { 3-noded triangular } \\
\text { general-purpose } \\
\text { shell }\end{array}$ & $\begin{array}{l}\mathrm{E}_{11}=9600 \mathrm{MPa} ; \mathrm{E}_{22}=9600 \mathrm{MPa} \\
\mathrm{E}_{33}=17,800 \mathrm{MPa} ; \mathrm{G}_{12}=3097 \mathrm{MPa} \\
\mathrm{G}_{13}=3510 \mathrm{MPa} ; \mathrm{G}_{23}=3510 \mathrm{MPa} \\
v_{12}=0.55 ; v_{13}=0.30 ; v_{23}=0.30\end{array}$ & Rho [17]; Cowin [18] \\
\hline Cancellous bone & 4-noded tetrahedral & $\begin{array}{l}\mathrm{E}_{11}=144 \mathrm{MPa} ; \mathrm{E}_{22}=99 \mathrm{MPa} \\
\mathrm{E}_{33}=344 \mathrm{MPa} ; \mathrm{G}_{12}=53 \mathrm{MPa} \\
\mathrm{G}_{13}=45 \mathrm{MPa} ; \mathrm{G}_{23}=63 \mathrm{MPa} \\
v_{12}=0.23 ; v_{13}=0.17 ; v_{23}=0.11\end{array}$ & Ulrich et al. [19] \\
\hline Posterior elements & 4-noded tetrahedral & $\mathrm{E}=3500 \mathrm{MPa} ; v=0.29$ & Kumaresan et al. [20] \\
\hline Annulus fibrosus & 4-noded tetrahedral & $\begin{array}{l}\text { Ground substance: } \mathrm{E}=4.2 \mathrm{MPa} ; v=0.45 \\
\text { Elastic fibers: } \mathrm{E}=450 \mathrm{MPa} ; v=0.30\end{array}$ & Ha et al. [21] \\
\hline Nucleus pulposus & 8-noded brick & $\mathrm{E}=1.0 \mathrm{MPa} ; v=0.499$ & $\begin{array}{l}\text { Ha et al. [21] } \\
\text { Brolin and Halldin [22] }\end{array}$ \\
\hline Endplates & 4-noded tetrahedral & $\mathrm{E}=500 \mathrm{MPa} ; v=0.40$ & Yoganandan et al. [23] \\
\hline ALL & 2-noded tension-only link & $\mathrm{E}=30.0 \mathrm{MPa} ; v=0.30$ & Zhang et al. [24] \\
\hline PLL & 2-noded tension-only link & $\mathrm{E}=20.0 \mathrm{MPa} ; v=0.30$ & Zhang et al. [24] \\
\hline ISL, LF (C1-C2) & 2-noded tension-only link & $\mathrm{E}=10.0 \mathrm{MPa} ; v=0.30$ & Zhang et al. [24] \\
\hline SSL, ISL, LF (C2-C7) & 2-noded tension-only link & $\mathrm{E}=1.5 \mathrm{MPa} ; v=0.30$ & Zhang et al. [24] \\
\hline CL (C1-C3) & 2-noded tension-only link & $\mathrm{E}=10.0 \mathrm{MPa} ; v=0.30$ & Zhang et al. [24] \\
\hline CL (C3-C7) & 2-noded tension-only link & $\mathrm{E}=20.0 \mathrm{MPa} ; v=0.30$ & Zhang et al. [24] \\
\hline A1L & 2-noded tension-only link & $\mathrm{E}=5.0 \mathrm{MPa} ; \mathrm{v}=0.30$ & Zhang et al. [24] \\
\hline TL & 2-noded tension-only link & $\mathrm{E}=20.0 \mathrm{MPa} ; v=0.30$ & Zhang et al. [24] \\
\hline ApL & 2-noded tension-only link & $\mathrm{E}=20.0 \mathrm{MPa} ; v=0.30$ & Zhang et al. [24] \\
\hline
\end{tabular}

Table 2. Values of R and S, as computed from the \% changes in the $\sigma_{\mathrm{MVM}}, \mathrm{MSED}, \mathrm{LF}$, and ROM results.

\begin{tabular}{ccccccccrr}
\hline $\begin{array}{c}\text { Discectomy method } \\
\begin{array}{c}\text { Simulated } \\
\text { (model designation) }\end{array}\end{array}$ & R1 & S1 & R2 & S2 & R3 & S3 & R4 & S4 & CBPI \\
\hline CONDIS & 66 & 126 & 87 & 126 & 35 & 35 & 3 & 18 & 2.38 \\
MIVDIS & 82 & 154 & 107 & 154 & 35 & 42 & 3 & 18 & 2.23 \\
\hline
\end{tabular}

degrees of freedom.

For each of the models, seven different loadings were applied, these being 1) $1 \mathrm{Nm}$ sagittal plane (flexion) moment +73.6 $\mathrm{N}$ axial compressive pre-load; 2) $1 \mathrm{Nm}$ sagittal plane (extension) moment $+73.6 \mathrm{~N}$ axial compressive pre-load; 3) $1 \mathrm{Nm}$ left lateral bending moment +73.6 $\mathrm{N}$ axial compressive pre-load; 4) $1 \mathrm{Nm}$ right lateral bending moment $+73.6 \mathrm{~N}$ axial compression preload; 5) $1 \mathrm{Nm}$ clockwise-acting axial rotational moment +73.6 N axial compression pre-load; 6) $1 \mathrm{Nm}$ counterclockwise-acting axial rotational moment $+73.6 \mathrm{~N}$ axial compression pre-load; and 7) an axial compression force of $250 \mathrm{~N}$ only. Note that (a) for each of the loadings 1)-6), the pre-load was appliednormal to the surface of the superior endplate of the C1 vertebral body, as a uniform pressure of $0.13 \mathrm{MPa}$ (the area of this superior surface $-556 \mathrm{~mm}^{2}$ — was obtained using the "Query Area Properties” feature in ABAQUS ${ }^{\circledR} 6.4$ ); (b) loading 7) was applied as a uniform pressure of $0.45 \mathrm{MPa}$; and (c) each of the moments was applied as a coupled load to the aforementioned surface. Note that 1) the axial compressive pre-load corresponds to the weight of the head of an adult male [1,31,32], and 2) the magnitudes of each of the moments and the axial compression force are within the rangestelemetrically measured during a variety of activities of daily living in a group of patients [33].

\subsection{Parameters Determined}

For each combination of model (INT, CONDIS, and MIVDIS Models) and applied loading, the parameters determined were 1 ) maximum von Mises stress ( $\sigma_{\mathrm{MVM}}$ ) in a series of hard tissues at the C5-C6 level;2) maximum strain energy density (MSED) in each of the aforementioned tissues; 3) $\sigma_{\mathrm{MVM}}$ and MSED in each of a series of hard tissues at the C4-C5 level; 4) $\sigma_{\mathrm{MVM}}$ and MSED for the superior endplate at $\mathrm{C7}$, the annulus of the C6-C7 disc, and the nucleus of the C6-C7 disc; 5) the force in each of the ligaments (LF) at the C5-C6 level; and 6) the total principal rotation angle or range of motion (ROM) at each of the six intersegmental positions. We used items 3) and 4) as examples of the biomechanical response at levels above and below the level of simulated discectomy, respectively. We point out that $\sigma_{\mathrm{MVM}}$ and MSED were not determined for the bony is- 
sues at the C7 level because it is very likely that the results will be artifactual; that is, they will not be true measures of responses to the applied loading because the model was fully constrained at the inferior surface of C7. For a given tissue, we used $\sigma_{\mathrm{MVM}}$ and MSED as indices of the stress-strain state in it, while ROM provides an indication of how much compromise the patient may experience in terms of fulfilling the kinematics requirements for performing normal activities of daily living.

For each combination of simulated discectomy model and applied loading, we calculated the \% change of each of the biomechanical parameters determined, relative to the corresponding value when INT model was used. A \% change may thus be considered as ameasure of the extent to which the biomechanical functions of the spine are affected by the variant of discectomy technique simulated.

For a given simulated discectomy model, we calculated the value of a parameter, which we call the composite biomechanical performance index (CBPI) [25], thus:

$$
\mathrm{CBPI}=\mathrm{R} 1 / \mathrm{S} 1+\mathrm{R} 2 / \mathrm{S} 2+\mathrm{R} 3 / \mathrm{S} 3+\mathrm{R} 4 / \mathrm{S} 4,
$$

where $\mathrm{R} 1$ is the number of times the \% change in $\sigma_{\mathrm{MVM}}$ exceeds $10 \%$, S1 is the total number of results of $\%$ change in $\sigma_{\mathrm{MVM}}, \mathrm{R} 2$ is the number of times the \% change in MSED exceeds $10 \%$, S2 is the total number of results of \% change in MSED , R3 is the number of times the \% change in the force in a given ligament exceeds $10 \%$, S3 is the total number of results of \% change in ligament force, R4 is the number of times the \% change in ROM exceeds $10 \%$, and S4 is the total number of results of \% change in ROM.

In other words,CBPImay be regarded as a comprehensive biomechanical parameter in that it incorporates changes in stress and strain of both hard and soft tissues as well as in kinematics of all the intersegmental positions, under a specified loading. Thus, CBPI is a plausible parameter to use in comparing the relative sensitivities of the biomechanical responses of the two simulated discectomy models to the collection of applied loadings imposed.

\section{RESULTS}

Because of the large volume of these results (specifically, 7sets of $\sigma_{\mathrm{MVM}}$ results, 7 sets of MSED results, 7 sets of ligament force results, and 3 sets of ROM results, with each set containing results for the three models), we only present a small sample (Figures 2-5). We point out that the three main trends seen in these results are the same as those seen in the rest of the whole collection of results. The first trend is that 1 ) with four exceptions, $\sigma_{\mathrm{MVM}}$ in a given tissue is about the same when CONDIS model or MIVDIS Model is used. The exceptions are in the AF in the disc at C4-C5 ( 7 times higher when the MIVDIS Model was used); the posterior elements on the C5 vertebral body ( $\sim 5$ times higher when CONDIS Model was used); the cortical bone of the C6 vertebral body ( 8 times higher when MIVDIS Model was used); and the posterior elements on the C6 vertebral body ( 2 times higher when MIVDIS Model was used); 2) with three exceptions, MSED in a given tissue is about the same for both CONDIS and MIVDIS models. The exceptions are: the posterior elements on the C5 vertebral body ( 9 times higher when CONDIS Model was used); and cortical bone of the C6 vertebral body ( $\sim 2$ times higher when MIVDIS Model was used); and the posterior elements on the C6 vertebral body ( $\sim 2$ times higher when MIVDIS Model was used); and 3) with the exception of the ROM at C5-C6, ROM at a given intersegmental position is about the same for both CONDIS and MIVDIS models. The second trend, which derives from the first, is that three hard tissues (the posterior elements on the C5 vertebral body, the cortical bone of the C6 vertebral body, and the posterior elements on the C6 vertebral body) are sensitive to the simulated discectomy technique used. This outcome is not surprising given that the simulated discectomy was of the disc at the C5-C6 level. The third trend is that the change in the force in each of the ligaments at C5-C6 was markedly lower when MIVDIS Model was used compared to when CONDIS Model was used.

A principal finding is that the difference in CBPI value when CONDIS Model was used compared to when MIVDIS Model was used is small ( 7\%) (Table 2).

\section{DISCUSSION}

There are two variants of cervical discectomy that are in clinical use; namely, the standard or open method and the minimally-invasive or percutaneous method [1,3-9]. There are no biomechanical comparisons of these two variants. The purpose of the present work was to conduct such a study, and we have done so by 1 ) simulating severe degeneration of the disc at the C5-C6 level (a common site of severe degeneration seen clinically), 2) utilizing a collection of applied loadings that are physiologically relevant, and 3) obtaining a wide collection of biomechanical parameters, including ROM. In other words, the present study may be regarded as being comprehensive, raising the possibility that the results obtained could be treated in such a way as to provide insights that may have clinical relevance.

Although both conventional and minimally-invasive techniques for cervical discectomy have been shown to be safe, efficacious, and with low rates of postoperative surgical site infections $[1,3,5-8,34]$, to the best of our 
knowledge, there are no literature reports (case studies, prospective data from surgical registries, or prospective, randomized, controlled trials) on comparison of these two variants on the basis of, for example, duration of surgery and clinical outcomes. This situation contrasts with that for lumbar discectomy, in which there are comparisons of conventional and minimally-invasive techniques on the basis of, for example, length of operating time, blood loss, duration of hospital stay, surgical complications, and outcome measures (such as changes in Visual Analogue Scale, Oswestry Disability Index, and the Core Outcome Measures Index after the surgery) and duration of hospital stay [35-37]), These comparisons found no significant difference in, for example, rate

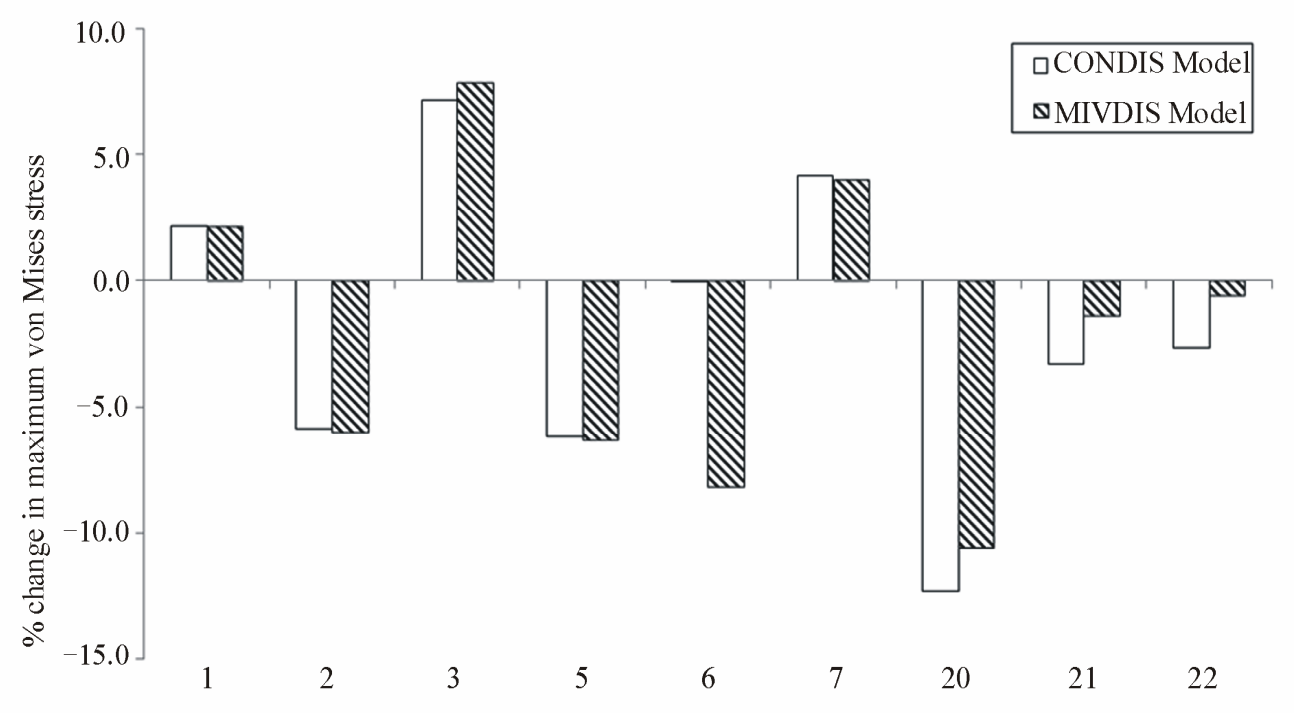

1 - C4 superior endplate; 2 - C4 cortical; 3 - C4 cancellous; 5 - C4 inferior endplate; 6 - IVD4-5 annulus; 7 - IVD4-5 nucleus; 20 - IVD6-7 annulus; 21 - IVD6-7 nucleus; 22 - C7 superior endplate

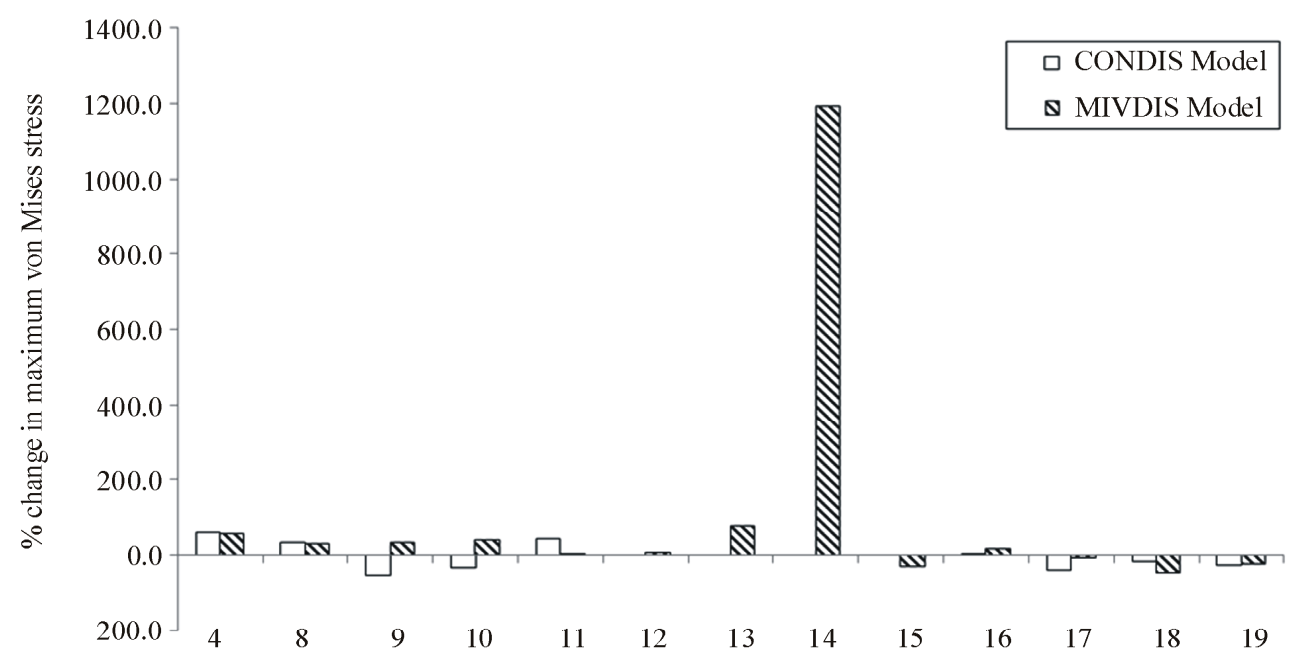

4 - C4 posterior elements; 8 - C5 superior endplate ; 9 - C5 cortical ; 10 - C5 cancellous; 11 - C5 posterior elements ; 12 - C5 inferior endplate; 13 - IVD5-6 annulus; 14 - IVD5-6 nucleus; 15 - C6 superior endplate ; 16 - C6 cortical; 17 - C6 cancellous; 18 - C6 posterior elements; 19 - C6 inferior endplate

Figure 2. Summary of the \% change in the maximum von Mises stress in a simulated discectomy model, under combined loading of $1 \mathrm{Nm}$ left lateral bending moment $+73.6 \mathrm{~N}$ axial compression pre-load, relative to the value when INT model was used. 


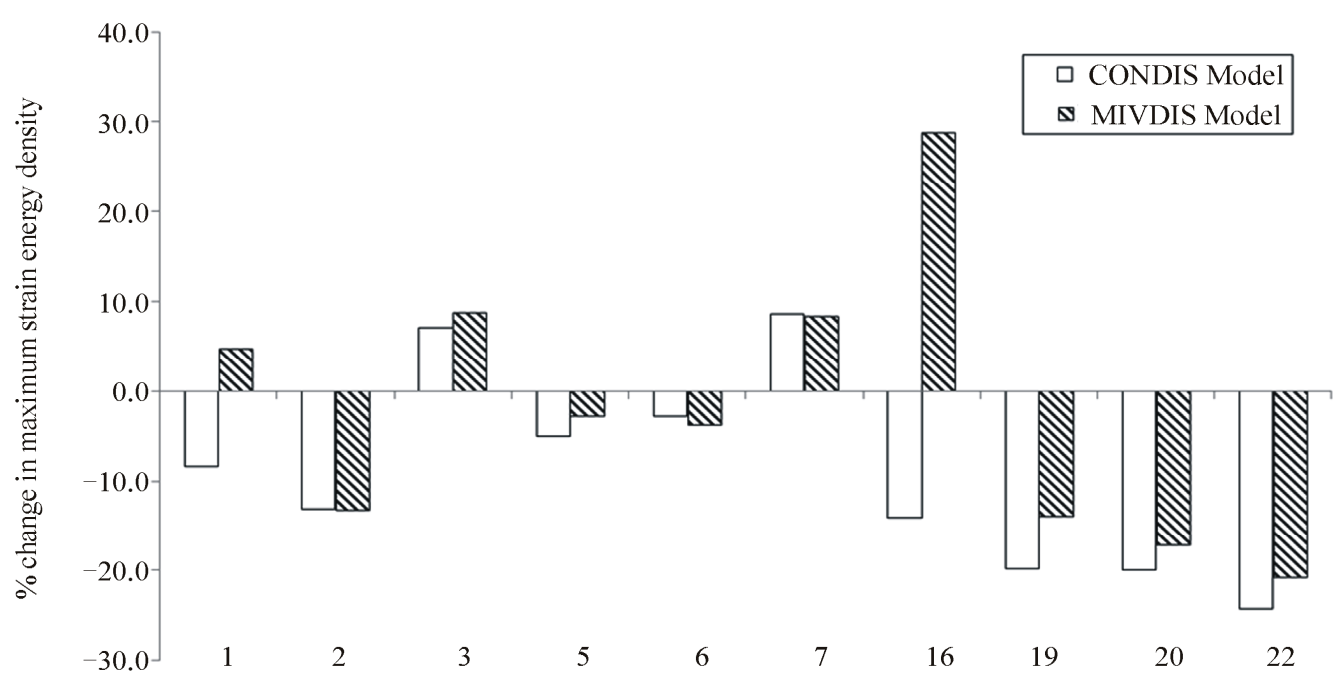

1 - C4 superior endplate; 2 - C4 cortical; 3 - C4 cancellous; 5 - C4 inferior endplate; 6 - IVD4-5 annulus; 7 - IVD4-5 nucleus; 16 -C6 cortical; 19 - C6 inferior endplate; 20 - IVD6-7 annulus; 22 - C7 superior endplate

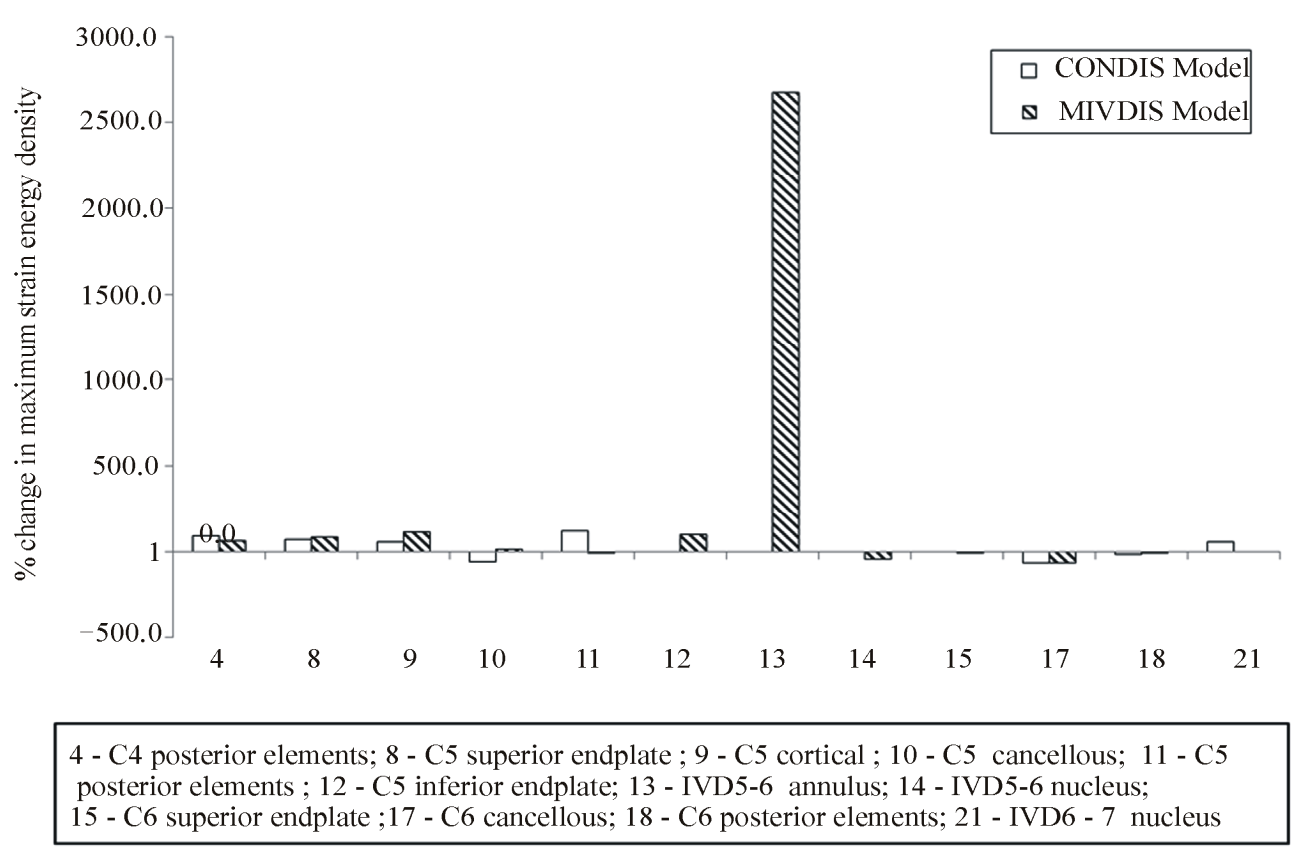

Figure 3. Summary of the \% change in the maximum strain energy density in a simulated discectomy model, under combined loading of $1 \mathrm{Nm}$ left lateral bending moment $+73.6 \mathrm{~N}$ axial compression preload, relative to the value when INT model was used.

of surgical complications, duration of hospital stay, and any outcome measures between the two variants [35-37].

In the present work, we utilized some simplifications, two key assumptions, and one caveat. Some of these simplifications are common to FEA studies of models of spine sections that contain a degenerated disc; for example, treating the geometry of the cancellous bone as a continuum [29,38-40], neglect of time-dependent effects in the AF and the NP [29,38-40], and neglect of the effect of tears in the AF $[39,40])$. Other simplifications are specific to the present study. We highlight two of these. First, our MIVDIS model does not, strictly speaking, correspond to any specific minimally-invasive technique used for cervical discectomy. This is because there is a variety of surgical approaches that are taken to accomplish minimally-invasive cervical discectomy [5-9]. The 


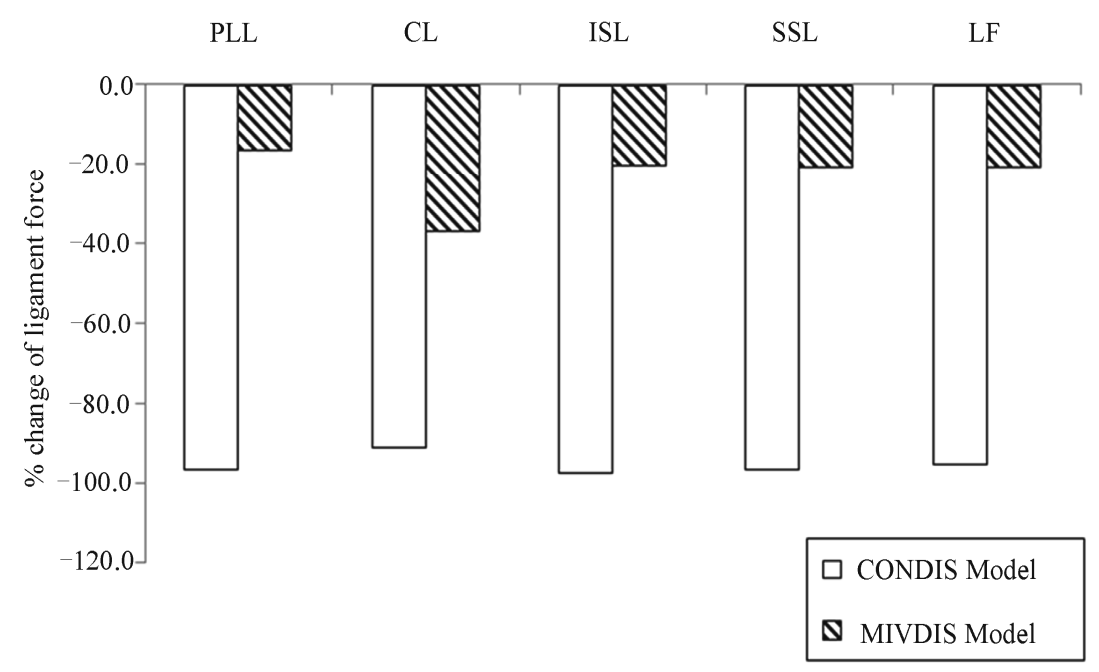

Figure 4. Summary of the \% changes in forces in various ligaments at the C5-C6 level in a simulated discectomy model, under a combined loading of $1 \mathrm{Nm}$ left lateral bending moment $+73.6 \mathrm{~N}$ axial compression pre-load, relative to the value when INT model was used.

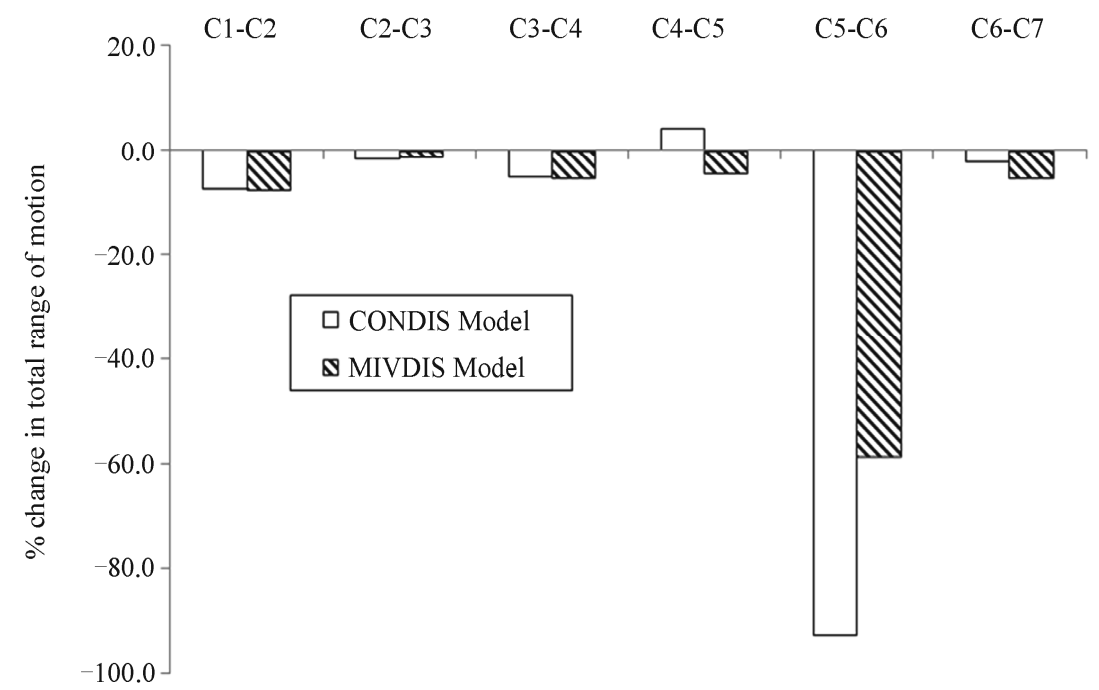

Figure 5. Summary of the \% changes in range of motions in a simulated discectomy model, under a combined loading of $1 \mathrm{Nm}$ left lateral bending moment $+73.6 \mathrm{~N}$ axial compression pre-load, relative to the value when INT model was used.

key point to note is that our approach is consistent with the essential elements of each of these surgical approaches [5-9]. The second specific simplification is that we modeled each of the two constituents of the AF (the ground substance and the reinforcing fibers) as well as the NP as isotropic, elastic solids. Although this constitutive material behavior model has been used for these tissues in a number of previous FEA studies of the cervical spine [31,41], many other material models have also been used, such as hyperelastic (Mooney-Rivlin) or hyperelastic (neo-Hookean) for the ground substance
[42], nonlinear stress-strain relationship for the AF fibers [43]; incompressible fluid for the NP [29]; and poroelasticity for both the AF and the NP [44]. The issue of the influence that the material models used for the AF and the NP exerts on the results obtained using the present models was outside the scope of the present study. The first assumption used was that, in INT model, the only degenerated tissue is the disc at C5-C6. It is possible, however, that discs at other levels may be degenerated. The second assumption made was that the line of action of the pre-load passes through the instantaneous center 
of rotation of $\mathrm{C} 1$ and, hence, the load does not generate an additional moment about that axis. Most likely, this is what happens except, perhaps, when axial rotation moment is applied [45]. The caveat is that we used $10 \%$ change as the cutoff value in obtaining the value of the parameter, R. Although this cutoff value is arbitrary, it is plausible because it is based on a clinical result. For a group of 29 healthy, adult volunteers, Watanabe et al. [46] found an increase of $\sim 11 \%$ in the mean value of axial relaxation time for the AF in lumbar discs, obtained using magnetic resonance imaging, in going from a healthy disc to a severely degenerated one.

Four important limitations of our study are discussed. First, the facet joints were not explicitly included in the solid model; rather, they were modeled as part of the posterior elements. For a C4-C6 model, the principal and coupled motions, under a loading of either $1.8 \mathrm{Nm}$ flexion $+73.6 \mathrm{~N}$ compression pre-load or $1.8 \mathrm{Nm}$ extension $+73.6 \mathrm{~N}$ compression pre-load, ranged from being $11 \%$ lower to $28 \%$ higher when facet joints were not explicitly included in the model [42] compared to corresponding results when they were (Ha et al. [21]). We expect this trend to be the same when a full cervical spine model is used. Second, the muscles of the cervical spine were not included in the solid model, but it is realized that muscle forces have an important influence on spinal motions. Third, shear forces were not included in the suite of loadings used. We are, however, not aware of any literature reports in which the response to the cervical spine under shear load is documented, which means it would not have been possible to validate our FEA model (INT model) under shear load.

The aforementioned simplifications, assumptions, and limitations do not undermine the validity of our work because the principal trend in our study, namely, the small difference in CBPI values for the two simulated discectomy models, is consistent with relevant clinical observations [35-37].The significance of our study is that its principal finding may be interpreted as buttressing the clinical view, which is that, at the current stage of development, a minimally-invasive technique for cervical discectomy has a number of benefits but the decision to use it should be made by the surgeon on a caseby-case basis, guided by very strict patient inclusion criteria, especially the specifics of the disc degenerative disease [35-37].

\section{CONCLUSIONS}

- On the basis of the value of an index of the biomechanical performance of a model of the full cervical spine that has been shown to be plausible, we found that the overall performance of a model in which minimally-invasive discectomy at C5-C6 was simu- lated was about the same as when a conventional discectomy technique was simulated.

- The aforementioned trend is the same as that reported on the comparative complications rate and outcome measures of these two variants of discectomy in the case of the lumbar spine.

- From a healthcare perspective, one implication of our principal finding is that minimally-invasive cervical discectomy should be considered an attractive option provided that detailed patient inclusion criteria are clearly defined and strictly followed.

\section{REFERENCES}

[1] Hauerberg, J., Kosteljanetz, M., Bøge-Rasmussen, T., Dons, K., Gideon, P., Springborg, J.B., and Wagner, A. (2008) Anterior cervical discectomy with or without fusion with Ray titanium cage: A prospective randomized clinical study. Spine, 33, 458-464. doi:10.1097/BRS.0b013e3181657dac

[2] Anderson, P.A., Subach, B.R., and Riew, K.D. (2009) Predictors of outcome after anterior cervical discectomy and fusion: A multivariate analysis. Spine, 34, 161-166. doi:10.1097/BRS.0b013e31819286ea

[3] Nandoe-Tiwari, R.D.S., Bartels, R.H.M.A., and Peul, W.C. (2006) Long-term outcomes after anterior cervical discectomy without fusion. European Spine Journal, 16, 1411-1416. doi:10.1007/s00586-007-0309-y

[4] Rao, R.J., Christie, J.G., Ghahreman, A., Cartwright, C.A. and Ferch, R.D. (2008) Clinical and functional outcomes of anterior cervical discectomy without fusion. Journal of Clinical Neuroscience, 15, 1354-1359. doi:10.1016/j.jocn.2007.12.009

[5] Chiu, J.C., Clifford, T.J., Greenspan, M., Richley, R.C., Lohman, G. and Sison, R.B. (2007) Percutaneous microdecompressive endoscopic cervical discectomy with laser thermodiskoplasty. Mount Sinai Journal of Medicine, 67, 278-282.

[6] Ahn, Y., Lee, S.H., Lee, S.C., Shin, S.W. and Chung, S.E. (2004) Factors predicting excellent outcome of percutaneous cervical discectomy: Analysis of 111 consecutive cases. Neuroradiology, 46, 378-384. doi:10.1007/s00234-004-1197-z

[7] Aydin, Y., Kaya, A., Can, S.M., Turkmenoglu, O., Cavusoglu, H., and Ziyal, I.M. (2005) Minimally invasive anterior contralateral approach for the treatment of cervical disc herniation. Surgical Neurology, 63, 210-219. doi:10.1016/j.surneu.2004.07.001

[8] Lee, S-H., J.H.M., Choi, W.-C., Jung, B. and Mehta, R. (2007) Anterior minimally invasive approaches for the cervical spine. Orthopaedic Clinics of North America, 38, 327-337. doi:10.1016/j.ocl.2007.02.007

[9] Ahn, Y., Lee, S.H. and Shin, S.W. (2005) Percutaneous endoscopic cervical discectomy: Clinical outcome and radiographic changes. Photomedicine and Laser Surgery, 23, 362-368. doi:10.1089/pho.2005.23.362

[10] Kotilainen, E. (1999) Percutaneous nucleotomy in the treatment of cervical disc herniation: Report of three cases and a review. Minimally Invasive Neurosurgery, 42, 
152-155. doi:10.1055/s-2008-1053389

[11] Bertagnoli, R. (2008) Single level ProDisc ${ }^{\circledR}-\mathrm{C}$ total disc replacement up to four years follow-up. The Spine Journal, 8, 75S. doi:10.1016/j.spinee.2008.06.177

[12] Phillips, F.M., Allen, T.R., Regan, J.J., Albert, T.J., Cappuccino, A., Devine, J.G., Ahrens, J.E., Hipp, J.A. and McAfee, P.C. (2009) Cervical disc replacement in patients with and without previous adjacent level fusion surgery: A prospective study. Spine, 34, 556-565. doi:10.1097/BRS.0b013e31819b061c

[13] Xu, J.-X., Zhang, Y.-Z., Shen, Y., and Ding, W.-Y. (2009) Effect of modified techniques in Bryan cervical disc arthroplasty. Spine, 34, 1012-1017. doi:10.1097/BRS.0b013e31819c4a5b

[14] Donkersloot, P. (2009) Nucleus replacement with the DASCOR $^{\circledR}$ disc arthroplasty system: Two-year follow-up results of the European multicenter clinical studies. Surgical Neurology, 71, 140-141. doi:10.1016/j.surneu.2008.10.033

[15] Ruan, D., He, Q., Ding, Y., Hou, L., Li, J. and Luk, K.D.K. (2007) Intervertebral disc transplantation in the treatment of degenerative spine disease: A preliminary study. Lancet, 369, 993-999. doi:10.1016/S0140-6736(07)60496-6

[16] Oppenheimer, J.H., DeCastro, I. and McDonnell, D.E. (2009) Minimally invasive spine technology and minimally invasive spine surgery: A historical review. $\mathrm{Neu}$ rosurgery Focus, 27, 1-15.

[17] Rho, R.Y. (2000) Ultrasonic methods for evaluating mechanical properties of bone. In: An, Y.H. and Draughn, R.A., Eds. Mechanical Testing of Bone and Bone-Implant Interface, CRC Press, Boca Raton.

[18] Cowin, S.C. (2001) Bone Mechanics Handbook. 2nd Edition, CRC Press, Boca Raton.

[19] Ulrich, D., Rietbergen, B., Laib, A. and Ruegsegger, P. (1999) The ability of three-dimensional structural indices to reflect mechanical aspects of trabecular bone. Bone, 25, 55-60. doi:10.1016/S8756-3282(99)00098-8

[20] Kumaresan, S., Yoganandan, N. and Pintar, F.A. (1997) Finite element analysis of anterior cervical spine interbody fusion. Bio-Medical Materials and Engineering, 7, 221-230.

[21] Ha, S.K. (2006) Finite element modeling of multi-level cervical spinal segments (C3-C6) and biomechanical analysis of an elastomer-type prosthetic disc. Medical Engineering \& Physics, 28, 534-541. doi:10.1016/j.medengphy.2005.09.006

[22] Brolin, K. and Halldin, P. (2004) Development of a finite element model of the upper cervical spine and a parameter study of ligament characteristics. Spine, 29, 376-385. doi:10.1097/01.BRS.0000090820.99182.2D

[23] Yoganandan, N., Kumaresan, S.C, Voo, L., Pintar, F.A and Larson, S.J. (1996) Finite element modeling of the C4-C6 cervical spine unit. Medical Engineering \& Physics, 16, 569-574. doi:10.1016/1350-4533(96)00013-6

[24] Zhang, Q.H., Teo, E.C., Ng, H.W. and Lee, V.S. (2006) Finite element analysis of moment-rotation relationships for human cervical spine. Journal of Biomechanics, 39, 189-193. doi:10.1016/j.jbiomech.2004.10.029

[25] Li, Y. and Lewis, G. (2010) Influence of surgical treatment for disc degeneration disease at C5-C6 on changes in some biomechanical parameters of the cervical spine.
Medical Engineering \& Physics, 32, 595-603. doi:10.1016/j.medengphy.2010.02.009

[26] Panjabi, M.M., Crisco, J.J., Vasavada, A., Oda, T., Cholewicki, J., Nibu, K. and Shin, E. (2001) Mechanical properties of the human cervical spine as shown by three-dimensional load-displacement curves. Spine, 26, 2692-2700. doi:10.1097/00007632-200112150-00012

[27] Wheeldon, J.A., Pintar, F.A., Knowles, S. and Yoganandan, N. (2006) Experimental flexion/extension data corridors for validation of finite element models of the young, normal cervical spine. Journal of Biomechanics, 39, 375-380. doi:10.1016/j.jbiomech.2004.11.014

[28] Mehalic, T.F., Pezzuti, R.T. and Applebaum, B.I. (1990) Magnetic resonance imaging and cervical spondylotic myelography. Neurosurgery, 26, 217-227. doi:10.1227/00006123-199002000-00006

[29] Kumaresan, S., Yoganandan, N., Pintar, F.A., Maiman, D.J. and Goel, V.K. (2001) Contribution of disc degeneration to osteophyte formation in the cervical spine: A biomechanical investigation. Journal of Orthopaedic Research, 19, 977-984. doi:10.1016/S0736-0266(01)00010-9

[30] Kumaresan, S., Yogananadan, N., Pintar, F.A. and Maiman, D.J. (1999) Finite element modeling of the cervical spine: Role of intervertebral disc under axial and eccentric loads. Medical Engineering \& Physics, 21, 689-700. doi:10.1016/S1350-4533(00)00002-3

[31] Galbusera, F., Fantigrossi, A., Raimondi, M.T., Sassi, M., Fornari, M. and Assietti, R. (2006) Biomechanics of the C5-C6 spinal unit before and after placement of a disc prosthesis. Biomechanics and Modeling in Mechanobiology, 5, 253-261. doi:10.1007/s10237-006-0015-4

[32] Tchako, A. and Sadegh, A. (2009) Stress changes in intervertebral discs of the cervical spine due to partial discectomies and fusion. Journal of Biomechanical Engineering, 131, 1-11. doi:10.1115/1.3118763

[33] Rohlmann, A., Graichen, F., Bender, A., Kayser, R. and Bergmann, G. (2008) Loads on a telemetrized vertebral body replacement measured in three patients within the first operative month. Clinical Biomechanics, 23, 147158. doi:10.1016/j.clinbiomech.2007.09.011

[34] O’Toole, J.E., Eichholz, K.M. and Fessler, R.G. (2009) Surgical site infection rates after minimally invasive spinal surgery. Journal of Neurosurgery: Spine, 11, 471-476. doi:10.3171/2009.5.SPINE08633

[35] Franke, J., Greiner-Perth, R., Boehm, H., Mahfeld, K., Grasshoff, H., Allam, Y. and Awiszus, F. (2009) Comparison of a minimally invasive procedure versus standard microscopic discectomy: A prospective controlled clinical trial. European Spine Journal, 18, 992-1000. doi:10.1007/s00586-009-0964-2

[36] Porchet, F., Bartanusz, V., Kleinstueck, F.S., Lattig, F., Jeszenszky, D., Grob D. and Mannion, A.F. (2009) Microdiscectomy compared with standard discectomy: An old problem revisited with new outcome measures within the framework of a spine surgical registry. European Spine Journal, 18, S360-S366. doi:10.1007/s00586-009-0917-9

[37] Veresciagina, K., Spakauskus, B. and Ambrozaitis, K.V. (2010) Clinical outcomes of patients with lumbar disc herniation, selected for one-level open-discectomy and micodiscectomy. European Spine Journal, 19, 1450-1458. 
doi:10.1007/s00586-010-1431-9

[38] Rohlmann, A., Zander, T., Schmidt, H., Wilke, H.-J. and Bergmann. G. (2006) Analysis of the influence of disc degeneration on the mechanical behaviour of a lumbar motion segment using the finite element method. Journal of Biomechanics, 39, 2484-2490. doi:10.1016/j.jbiomech.2005.07.026

[39] Schmidt, H., Kettler, A., Rohlmann, A., Claes, L. and Wilke, H.-J. (2007) The risk of disc prolapses with complex loading in different degrees of disc degeneration: A finite element analysis. Clinical Biomechanics, 22, 988998. doi:10.1016/j.clinbiomech.2007.07.008

[40] Schmidt, H., Heuer, F. and Wilke, H.-J. (2009) Dependency of disc degeneration on shear and tensile strains between annular fiber layers for complex loads. Medical Engineering \& Physics, 31, 642-649. doi:10.1016/j.medengphy.2008.12.004

[41] Tchako, A. and Sadegh, A. (2009) Stress changes in intervertebral discs of the cervical spine due to partial discectomies and fusion. Journal of Biomechanical Engineering, 131, 051013-1-051013-11. doi: $10.1115 / 1.3118763$

[42] Li, Y. and Lewis, G. (2010) Influence of the constitutive material behavior model assigned to the annulus fibrosus and the nucleus pulposus on the biomechanical perform- ance of a model of the cervical spine: A finite element analysis study. Journal of Mechanics in Medicine and Biology, 10, 151-166. doi:10.1142/S0219519410003216

[43] Natarajan, R.N., Chen, B.H., An, H.S. and Andersson, G.B.J. (2000) Anterior cervical fusion: A finite element model study on motion segment stability including the effect of osteoporosis. Spine, 25, 955-961. doi:10.1097/00007632-200004150-00010

[44] Jones, A.C. and Wilcox, R.K. (2008) Finite element analysis of the spine: Towards a framework of verification, validation and sensitivity analysis. Medical Engineering \& Physics, 30, 1287-1304. doi:10.1016/j.medengphy.2008.09.006

[45] Schmidt, H., Heuer, F., Claes, L. and Wilke, H.J. (2008) The relation between instantaneous center of rotation and facet joint forces: A finite element analysis. Clinical Biomechanics, 23, 270-278. doi:10.1016/j.clinbiomech.2007.10.001

[46] Watanabe, A., Benneker, L.M., Boesch, C., Watanabe, T., Obata T. and Anderson S.E. (2007) Classification of intervertebral disk degeneration with axial $\mathrm{T} 2$ mapping. American Journal of Roentgenology, 189, 936-942. doi:10.2214/AJR.07.2142 